\title{
university
of the arts
london
}

\begin{tabular}{|l|l|}
\hline Title & The Photo Essay: Patrick Sutherland \\
\hline Type & Article \\
\hline URL & https://ualresearchonline.arts.ac.uk/id/eprint/10525/ \\
\hline Date & 2016 \\
\hline Citation & $\begin{array}{l}\text { Sutherland, Patrick (2016) The Photo Essay: Patrick } \\
\text { Sutherland. Visual Anthropology Review, 32 (2).pp. 115- } \\
121 . \text { ISSN 1058-7187 }\end{array}$ \\
\hline Creators & Sutherland, Patrick \\
\hline
\end{tabular}

\section{Usage Guidelines}

Please refer to usage guidelines at

http://ualresearchonline.arts.ac.uk/policies.html or alternatively contact ualresearchonline@arts.ac.uk.

License: Creative Commons Attribution Non-commercial No Derivatives

Unless otherwise stated, copyright owned by the author 


\section{The Photo Essay}

\section{Patrick Sutherland University of the Arts London}

\section{Email: p.sutherland@lcc.arts.ac.uk}

Abstract: This invited essay reflects upon the use of the photo essay within documentary photography. In particular it compares Righteous Dopefiend, the muchlauded anthropological text by Philippe Bourgois with photographs by Jeff Schonberg, to work by photographers exploring similar subject matter. It aims to tease out some of the essential elements of the photo essay as well as the connections between the practices of visual anthropology, documentary photography and photojournalism. It is accompanied by a separate online article that describes an approach to shooting, editing and constructing a photo essay and offers guidelines for the submission of photo essays to VAR.

Author Bio: Patrick Sutherland is Professor of Documentary Photography at the University of the Arts London. For over two decades Patrick has been documenting the culturally Tibetan communities of Spiti in North India. The project has led to numerous exhibitions and the books Spiti The Forbidden Valley (2000) and Disciples of a Crazy Saint (2011) with Tashi Tsering. A photo essay entitled Spiti: some notes on the practice of documentary photography was published in Beyond text? Critical practices and sensory anthropology (2016).

Keywords: documentary photography; photojournalism; reportage photography; visual anthropology; drug addiction; the photo essay

\section{Introduction}

The photo essay reproduced on the previous pages was created by the acclaimed British photographer Roger Hutchings and edited specifically for an eight-page spread in Visual Anthropology Review. Hutchings first worked in the region when he went to document the plight of Iraqi Kurd refugees trapped on the mountainous border between Iraq and Turkey at the end of the first Gulf War. ${ }^{1}$ The experience was the stimulus for Hutchings to subsequently undertake a mostly self-financed, long-term documentation among Kurds in Southeast Turkey with journalist Jonathan Rugman between 1992 and 1996.

The photo essay is a narrative construction. It is associated primarily with masscirculation illustrated magazines, in particular LIFE magazine in the USA. ${ }^{2}$ Photo essays were once the primary vehicle for photojournalism, employing a format that combined the skills of journalists and photographers, sometimes working closely together. For many, the medium of photojournalism seems inseparable from such publications, which were both the source of funding for commissioned work 
produced by staff and freelancers and the vehicle for its distribution. However, photo essays are now regularly produced independently of magazines.

Classic magazine photo essays are primarily image-led, presenting a mix of photographs, captions, typography and short pieces of text in layouts spread over several pages. They operate as a form of collage, with images being read individually and also within a wider visual narrative. The effect of photo essays therefore depends not only upon the constituent images themselves but also on their interaction, the sequencing from the beginning of the essay to the end, as well as on the juxtapositions and contrasts established on the page. Designers laying out photo essays aim not only to construct a comprehensible narrative and to communicate information, but also to achieve visual and emotional impact through editing and design. Depending on the essay, the constituent elements could include, for example, photographs of key people who might be viewed as characters within a story, images that establish location, factual images that show important evidential details and make specific points, others that add a sense of atmosphere, dramatic and energetic images as well as more subtle, quiet pictures that provide variations in emotional impact.

Experienced photographers working for such magazines commonly presented the editor with a wide choice of material, often with variations of the same basic image. Such a selection offered flexibility to a designer needing to establish the overall structure and mood of the story. It gave the designer the opportunity to vary the layouts within the essay. Photographers provided verticals and horizontals, close ups, middle distance and long shots, images that could be used large, images that might function to open and close the sequence, images that could work small and images that could be used on a cover with typography laid over them. Although the best visually led magazine photo essays relied primarily on photographers to deliver the raw material it was unusual for them to be consulted on the final edit and layout.

Early magazine photo essays employed substantial amounts of writing in the form of titles, descriptive text, sub headings and captions that functioned to explain the photographs to the reader, to pin down and clarify their meaning. Photographic essays are essentially composed out of fragments. Text is often used to glue these disparate visual elements together and make sense of them, filling the narrative gaps between them and helping the reader navigate through the essay. ${ }^{3}$ More contemporary photo essays often assume a greater level of visual literacy in the viewer, the ability to make narrative connections between images, occasionally eschewing text altogether.

The decline of the illustrated magazine and the domination of television, the internet and social media as primary sources of news and visual information about the world combined with the move away by major newspapers from publishing serious visual essays in weekend supplements has undermined the status of the printed photo essay. But its essence, a series of photographs investigating and 
describing a specific theme, remains relevant and adaptable. For many decades, photographers have undertaken long-term self-initiated documentary photography projects and produced extended photo essays without funding from magazine commissions. ${ }^{4}$ Independence allows for greater editorial control over the selection and presentation of work.

Many documentary photography books involve bodies of work that are essentially photographic essays but presented in an alternative format. ${ }^{5}$ Advances in digital printing means that publishing and distributing documentary photo essays is easier than ever before and the photo essay presented on websites is now ubiquitous.

\section{Four examples of the photo essay}

Philippe Bourgois and Jeff Schonberg's celebrated book Righteous Dopefiend (2009) is an intimate, accessible and reflexive ethnography of drug addiction and homelessness as experienced by a small, marginalised group of middle-aged heroin and crack users in San Francisco. Researched over a decade, it delivers a rich narrative of the day by day individual and group struggles for economic and emotional survival, centred on their need to access heroin and to fund their habits.

This is an anthropological text, written from a medical and healthcare perspective. It provides an exceptional wealth of ethnographic detail about these users and their relationship with hard drug usage, the processes and technologies as well as the socio-economic imperatives of addiction. Amongst many themes, it explores what the authors refer to as a "moral economy of sharing" which offers these users some buffer of solidarity and support, albeit frequently betrayed.

The book mixes black and white reportage photographs with extensive recorded dialogue and extracts from field notes, all enmeshed within a wider critical and theoretical framework. It is an engrossing collage of materials. The writing gives voice to the participants, allowing them to speak in considerable depth about their experiences, their childhoods and inter-relationships with others, and offering a resonant perspective on the way they navigate through and comprehend the world they survive in.

The authors reference "collaborative photo ethnography" as part of their methodology. It is clear that the still camera, video camera, notebook, and audio recorder are key technologies used for their ethnographic fieldwork, providing a variety of materials for analysis. The medical anthropological focus of their research reveals, for example, that needles and syringes are used in identifiably different ways, according to ethnicity. The rituals of drug usage and injection are racially delineated, leading both to different embodied experiences of the effects of the drug and consequentially differing exposure to disease. "Skin popping," injecting into muscle, produces a slower more prolonged affect preferred by whites but risks producing abscesses whereas injecting intravenously, favoured by blacks and Hispanics, delivers a bigger rush but risks infection with blood borne disease. 
But the photographs in the book are not presented to evidence this kind of analysis or description and operate in different ways. They primarily add texture and atmosphere, communicating an intimation of space and place, bringing the individuals to life through their gestures of support and interaction and their expressions of homemaking within grungy living spaces. This visual material is richly descriptive and occasionally poetic, adding information that is hard to translate into words. One image depicts a white haired man, a small figure standing amongst trees whilst injecting himself in the hip. His cane, jacket, and shirt hang amongst a tangle of branches. It is an oddly elegiac moment, perhaps symbolic of an emotional wilderness and of nature engulfing the domestic.

The beautifully reproduced black and white photographs are presented as an introductory visual essay of twelve double page uncaptioned spreads and then as individual images or occasional small groupings punctuating the text. Photographs show key individuals, introduce chapters and illustrate the authors' themes. They detail the living conditions, the day to day lives and low level economic activities, as well as the relationships between users. They introduce individuals whose stories, voices and worldviews are explored in great depth through interviews. None of the photographs are directly accompanied by captions, inviting the viewer to decode the images themselves, but every image is presented again as a captioned thumbnail at the back of the book.

It is revealing to compare Righteous Dopefiend with three other photographic projects that share the territory of representing hard drug usage and to compare this work of anthropology with historical and contemporary photojournalism and documentary photography.

Bill Eppridge's sixteen page, black and white photo essay on drug addiction produced for LIFE Magazine and published on Feb 26 1965, is rightly viewed as one of the magazine's classic essays. ${ }^{6}$ The eight double-page layouts, uninterrupted by adverts, are followed by an extended essay entitled "The World of Needle Park," written by journalist James Mills. ${ }^{7}$ According to the editor's note, Mills spent two weeks working alongside the New York City Narcotics Bureau before identifying Karen and John, the two heroin users featured in the story. Eppridge and Mills then spent two months in almost continual contact with them, winning their confidence, learning their "language" so as to be accepted as insiders, engaging with their worldview and in the editor's words becoming "square denizens of the junkie world."

The layout of Eppridge's photo essay uses two photographs as double page spreads, a full page of text, a single full-page spread, filmic sequences of Karen assisting a fellow user after he has taken an overdose and other groupings of pictures describing their lives as junkies and petty criminals, in and out of hospital and jail. There are thirty-four photographs in the photo essay and four used as illustrations in Mills' following article. Images are cropped into a wide variety of different shapes. Every image is contextualised by detailed and descriptive captions, fixing meaning and reducing the potential for alternative readings. The opening image is a full 
bleed double page spread with title and caption overlaid on the image and the essay ends with a double page spread with overlaid caption.

The narrative structure of the essay is quite transparent: this presentation is a story with a beginning, a middle and an end. It revolves around identifiable, named characters with whom the reader is invited to identify. It contains moments of high drama and emotional release. Yet it also presents this story framed by a factual report written with a tone of concerned moral journalism. Drug usage is seen as an under-reported social problem with victims who are presented in the opening spread as quintessentially ordinary, recognisable (and white) Americans and as an attractive young couple. This essay is one of two editions of the magazine to highlight and campaign for governmental response to the then growing issue of heroin usage.

A key element of the LIFE Magazine essay is the drama and pacing offered by varying the size of images on the page. A full bleed double page spread adds huge visual impact, especially when employing a close up image. ${ }^{8}$ Alternatively, large images allow for the possibility of using photographs that contain fine detail or contribute a sense of space and place. Smaller pictures can then be used to make particular points within the essay or to draw the reader or viewer into a closer reading of the imagery. The use of sequences adds a filmic quality, a clear sense of action unfolding within a time frame. The use of very large spreads to open and close Eppridge's essay emphasises its visual rather than textual foundation. The photographs are edited as much for their emotional effect as for their informational content and the essay evidences numerous expressions of heightened states of feeling. The written journalism in the seven page textual essay that follows provides depth to the investigation, an abundance of observational detail and extensive use of quotations from interviews.

In sharp contrast, Larry Clark's book Tulsa (1971) barely employs text at all. ${ }^{9}$ After a short and infamous five line statement by the photographer, making it clear that he is an insider and user photographing amongst amphetamine injecting friends, Clark presents an "autobiographical," often morbid work avoiding any sense of journalistic or ethical distance, describing and often celebrating the drug usage, gun ownership and sexual activities of a group of friends living in Oklahoma in the 1960s.

The images are mainly reproduced as single pictures on the page with substantial white space around them: harsh and gritty documentary images but presented in an art book format rather than anything approaching a magazine layout. ${ }^{10}$ The images are mainly of men injecting themselves or injecting half naked women, and men playing with guns or sitting alone, strung out and lost in reverie. The cover photograph of a man posing half naked with a handgun, cool and self aware, is overlaid with the title. The same image is reproduced partway through the book with the caption "dead 1970" underneath. On the page opposite are the words "death is more perfect than life." Many of the photographs are portraits, often replete with anxiety, tension or aggression. 
Further on is a grainy, slightly ethereal image of a heavily pregnant seated woman with a tourniquet around her upper arm. She is injecting herself, apparently alone, in a white room. It is followed by an image of a woman carrying flowers, which in turn is followed by an image of an older man laying flowers by the open coffin of a baby (suggesting, perhaps, the pregnant woman's dead child). Then comes a sequence of photographs of a man labelled as a police informer being beaten up. The subsequent and final group of images are of young Americans shooting up and happily partying, of hard drug usage and graphic depictions of sexuality. The book contains only eight short pieces of text amongst the fifty photographs: two names, two dates, two very minimal captions and two short quotes. Readers are left free to interpret the images. Tulsa is a raw and nihilistic book devoid of moral tone, perhaps indicative of a certain kind of outlaw user mentality.

Tulsa and many of Clark's other works have faced accusations of exploitation and prurience. Voyeurism is a potential element of all observational documentary photography but part of the potency of Clark's work is his eager embrace of it. Clark's book sidesteps the reflexivity and awareness of the ethical issues of representation that makes Righteous Dopefiend such a deeply layered text. It makes no attempt to describe the nature of the relationships, economic or otherwise, between the men and women depicted or their thoughts about being represented on film or performing before the camera. Nevertheless Clark is a major figure in photographic history, his visceral and disturbing works a clear influence on photographers like Nan Goldin, Robert Mapplethorpe, and Antoine D'Agata who have pursued similarly unflinching autobiographical depictions of their lives.

Eugene Richards is one of the world's great contemporary photojournalists and Cocaine True Cocaine Blue (1994) is an intense work, examining the US inner city crack "epidemic," revealing in depth how the culture of cocaine usage operates, documenting its wider effects, and locating it within a framework of poverty and socio-economic disadvantage. Richards gives his photographs narrative primacy over the substantial sections of writing in the book. As a viewer you read the images first. They are never reduced to the role of illustrations dominated by explanatory text: images and words flow in parallel streams, informing and amplifying each other.

The visual essay reveals the experiences of its participants, documenting the drug's effect on individuals as well as its destructive role within the wider community. The work details the daily schedules of shooting up, smoking, coming down or overdosing. Richards goes deep inside a subculture, common to many US cities of the time, to reveal human liaisons, social groups with their own forms of behaviour and relationships of power as well as depicting the addiction-related economic realities of crime and prostitution.

The captions run alongside groupings of images, capturing their feel in personal and passionate authored journalism, which is never rigidly explanatory. Other text 
distilled from interviews is interspersed amongst the image sequences and provides a substantial sense of the voices of the participants and their struggles, histories and experiences. His perspective is profoundly humanistic, never losing empathy nor damning the people he is working among. Richards operates within a clear moral and critical framework. Though almost unbearingly intimate at times, the work avoids the voyeurism of Tulsa through the photographer's sensitivity to the rights of others. His subjects are not portrayed as passive victims but shown as active participants in a complex and destructive sub culture with its own logic, its own attractions and possibilities.

Cocaine True Cocaine Blue bears the hallmarks of a classic magazine photo essay but in a very substantially extended format. The book consists primarily of double page spreads and groupings of horizontal images butting up against each other. Pages of text and the occasional white space around images offer a breathing space from the relentless intensity of the photographic sequence. The images of human relationships contribute substantially to the grim emotional tone of the work. Many of the photographs are of interactions between people who are rarely depicted as communicating with each other or making eye contact. Their primary focus seems to be on the consumption of drugs. They appear isolated in their separate worlds, divorced from the everyday exchanges that comprise human society.

\section{Some comparisons}

Each of these four works deals very directly with the processes, social relationships and struggles involved in the worlds of hard drug usage. They all represent this subject matter through an extended series of documentary photographs and in some sense are all forms of the printed photo essay. What varies substantially between them is the relationship established between the use of images and text, the overall format of presentation and the intellectual framework behind the works, whether magazine journalism, anthropology, art-documentary practice or independent photojournalism.

Interestingly, they all contain recurring images of injecting, a visual expression of the repetitive mechanical realities of chemical dependency. Several contain images of the dead and funerals, or of overdosing and recovery, of outbursts of anger, loss of control and violence.

Eppridge's essay about the disintegrating lives of a young American couple offers up a cautionary tale of the dangers of the liberal sixties, perhaps a reaction against the emerging power of youth culture. James Mills's written essay contains very substantial observational detail, parallel in some ways to the written ethnography of Righteous Dopefiend though cast in the language of journalism. LIFE magazine was careful not to identify the drug dealer in the photographs but one wonders what effects the celebrity level exposure in the magazine had on the lives of Karen and John, including their ability to purchase drugs. 
Clark's project is presented as a participant and insider perspective and yet its lack of a contextualizing framework and the author's pursuit of notoriety, through the selection of imagery chosen often to shock, make it the most obviously exploitative and voyeuristic. But it does capture a substantial impression of the hedonistic pleasures of intoxication enjoyed by drug using subcultures. Other depictions of users primarily describe them satisfying a need and relieving the symptoms of pharmaceutical dependency.

Richards's book is the most sophisticated and detailed visual essay of the group. His work is so intimate, so physically close and so visually compelling that the viewer occasionally seems to enter the emotional and experiential space of the users, in images that seem to describe not just what crack consumption looks like, but what the experience feels like, the euphoria and the mania, the chaos and anxiety. It also contains substantial and engrossing texts that supplement, expand and contextualise the reading of the photography.

Nonetheless, there are clear limitations to the ability of photography to describe the complexities of human social experiences. Righteous Dopefiend by comparison with these three photographic works is heavily weighted to written text. The writings offer an unparalleled level of detail on the daily rituals, intricacies, survival strategies and life stories of drug using individuals and communities. Photographs and text offer separate but potentially overlapping streams of information. Photographs by themselves cannot present an analysis, construct a detailed argument, or lobby for specific changes in policy. Nor can they precisely frame human experiences within the context of economics, gender, and ethnicity in the way that Righteous Dopefiend does so successfully.

\section{Conclusion}

Still photography continues to hold some specific advantages over moving imagery. The frozen moment ruptures the flow of time, to preserve and potentially reveal. It presents a suspended stillness that offers the viewer time to read and allows for the opportunity to revisit an image repeatedly. Photography is also a less technologically complex process: documenting without audio and editing with a much looser form of sequencing, liberates the individual practitioner to work quickly and responsively. The extended photo essay or long term documentary project offers visual anthropologists the narrative potential of sequences of still imagery. But much of the power of projects like Righteous Dopefiend also lies in the collaborative and overlapping practices of an anthropologist and an anthropologically attuned photographer.

Each of the four projects discussed above was photographed using $35 \mathrm{~mm}$ cameras, once the established approach to photojournalism. Hand held small format cameras, whether film or digital, are ideally suited to capturing and revealing the intricacies and subtleties of human existence: people and their activities; social groupings and social interactions; the intimacies and complexities of human relationships; 
atmospheres, spaces and places; social institutions and peopled landscapes. But this is only one of many potential approaches that photographers currently employ. For a radically different take on the homeless in the US see Ben Murphy's precisely composed, large format, and unpeopled colour images of the temporary homes and possessions of the dispossessed in Los Angeles. Murphy's art documentary photographs, exhibited in galleries and museums as large prints, rely on the resolution of very fine informational detail. They are left open to narrative interpretation, unanchored by explanatory captioning. ${ }^{11}$

Documentary photography is a wide field of practice, an expanding spectrum of visual strategies, rather than a territory defined by specific subject matter or methodological approach. Writing in the form of descriptive captioning, authoritative explanatory statements and journalistic articles commonly accompanies the publication of photography in magazines. Text is widely employed to anchor the meaning and the reading of images. Such usage, with its tendency to reduce images to illustrations, acknowledges the fundamentally ambiguous nature of photographs. Contemporary photographic practices often employ a much freer relationship with text in an attempt to open up a more nuanced relationship between the separate mediums. Projects incorporate quotations, extensive interviews, personal diaristic writings, field notes, evidential written material gleaned from institutions or sometimes avoid text altogether.

It seems clear, however, that photographic projects completely devoid of text forego the depth of anthropological understanding and analysis exemplified by Righteous Dopefiend..$^{12}$ An ideal for visual anthropology might be to witness the emergence of work that combines the depth, commitment, detail and subtlety of this ethnographic field research and anthropological analysis with photography of the sophistication, intimacy and visual impact of Richards' Cocaine True Cocaine Blue. This is partly a question of scale and balance, of the photographic element of such potential works occupying a larger presence within the final output.

The camera is well established as a tool for ethnographic fieldworkers. Modern compact digital cameras have the reliable ability to produce high quality visual recordings of objects, places, people and occasions. But photography can be significantly more than a process of recording the world as everybody sees it. ${ }^{13}$ Undertaking an intimate, responsive and embodied reportage is a process of visual investigation that parallels ethnographic field note taking. It involves intense attention to detail and concentration on observation and recording. Serious visual documentation demands substantial commitment. It needs an understanding not only of the technology being employed but also of the potential of the medium to reveal as well as record and of the potential of the photo essay as an extended and varied narrative form. Visual anthropologists might well benefit from immersing themselves in the wide spectrum of contemporary documentary photography and photojournalism and published works employing the photo essay in order to critically and creatively reflect upon their own visual practices. 
[Note from the Editors: This essay is accompanied by a separate online article that describes an approach to learning documentary photography: shooting, editing and constructing a photo essay. Additionally it offers suggested guidelines for the submission of photo essays to VAR.]

\section{Acknowledgements}

I would like to thank Rupert Cox for inviting me to write this article for VAR and also Roger Hutchings for sharing his work on the Kurds and allowing me to collaborate in the editing.

\section{References}

Bourgois, Philippe and Jeff Schonberg. 2009. Righteous Dopefiend. Los Angeles: University of California Press.

Clark, Larry. Tulsa. 1971. New York: Lustrum Press.

Cox, Rupert, Andrew Irving and Christopher Wright, eds. Beyond text? Critical practices and sensory anthropology. Manchester: Manchester University Press.

Gardner, Robert and Karl G. Heider. 1968. Gardens of War. New York: Random House.

Lyon, Danny. 1971. Conversations with the Dead. New York: Henry Holt and Company.

Parr, Martin. 1999. Common Sense. Stockport: Dewi Lewis Publishing.

Richards, Eugene. 1994. Cocaine True Cocaine Blue. New York: Aperture.

Rugman, Jonathan and Hutchings, Roger. 1996. Ataturks Children: Turkey and the Kurds. London: Cassell.

Sutherland, Patrick. 2000. Spiti the Forbidden Valley. London: Network.

Sutherland, Patrick and Tsering, Tashi. 2011. Disciples of a Crazy Saint: The Buchen of Spiti. Oxford: Pitt Rivers Museum. 


\section{Notes}

${ }^{1}$ Photographs from the project have been widely used, including a spread for Die Zeit magazine, an exhibition at the Freedom Forum in London, and Rugman and Hutchings's book, Ataturk's Children (1996).

2 But also many other international publications including Look, National Geographic, the Sunday Times Magazine, Paris Match,and Stern for example.

3 The form of the photo essay is variable. Compare for example W. Eugene Smith's 1948 essay Country Doctor with the later 1951 essay Spanish Village. The latter uses much less descriptive text, delivering more visually based narrative structure.

4 See for example: Danny Lyon's Conversations with the Dead (1971).

${ }^{5}$ Robert Gardner and Karl Heider's 1965 book Gardens of War, a photographic reportage emerging from the 1961-63 Harvard Peabody expedition to the Baliem Valley in New Guinea is an interesting example of image-led visual anthropology. The palpable connection between the book layouts and editorial publications of the time is hardly surprising given that one of the seven contributing photographers to the project was Eliot Elisofon, a LIFE magazine staff photographer.

${ }^{6}$ Bill Eppridge was a LIFE Magazine staff photographer perhaps most famous for photographing the dying Robert Kennedy in 1968. As of July 2016, the photo essay could be viewed online:

https://books.google.co.uk/books?id=KEEEAAAAMBAJ\&printsec=frontcover\&sourc e=gbs_ge_summary_r\&cad $=0 \# v=$ onepage $\& q \& f=$ false

7 The bulk of LIFE magazine is dominated by adverts. James Mills' essay competes with full page adverts for alcohol and for cars.

${ }^{8}$ Life Magazine in 1965 was approximately 10.5 x 14 inches, giving a double page spread size of approximately 14 x 21 inches.

${ }^{9}$ Larry Clark is an infamous figure in documentary film and photography, author of numerous books including Tulsa, Teenage Lust, The Perfect Childhood and director of films including the controversial Kids.

10 Tulsa was first published by Lustrum Press, a small independent photography publisher. The book includes one double page spread, one sequence and two spreads containing film footage.

${ }^{11}$ http://www.benmurphy.co.uk/homes-of-the-american-dispossessed\#1 
12 There are exceptions to every rule however. Martin Parr's book Common Sense (1999) eschews text and yet is a fully understandable, witty, and forensic critique of tacky and tawdry consumer culture.

13 There is always a gap between what the world looks like through the camera viewfinder and what the resulting photograph looks like. This is one explanation of the street photographer Garry Winogrand's apparently tautological dictum "I photograph to find out what something will look like photographed."

\section{Citation}

Sutherland, P., 2016. 'The Photo Essay', Visual Anthropology Review, 32 (2): 115-121.

Visual Anthropology Review, Vol. 32, Issue 2, pp. 115-121, ISSN 1058-7187, online ISSN 1548-7458. 2016 by the American Anthropological Association. DOI: 10.1111/var.12103. 